\title{
Structure, Antimicrobial Activities and Mode of Interaction with Membranes of Bovel Phylloseptins from the Painted-Belly Leaf Frog, Phyllomedusa sauvagii
}

\author{
Zahid Raja ${ }^{1}$, Sonia André ${ }^{1}$, Christophe Piesse ${ }^{3}$, Denis Sereno ${ }^{2}$, Pierre Nicolas ${ }^{1}$, Thierry Foulon ${ }^{1}$, \\ Bruno Oury ${ }^{29}$, Ali Ladram ${ }^{1 * 9}$
}

1 UPMC Univ Paris 06, ER3 Biogenèse des Signaux Peptidiques (BIOSIPE), Paris, France, 2 Institut de Recherche pour le Développement (IRD), Unité Mixte de Recherche IRD 224-CNRS 5290-Univ Montpellier 1 et 2, Maladies infectieuses et Vecteurs: écologie, génétique, évolution et contrôle (MiVegec), Montpellier, France, 3 UPMC Univ Paris 06, IFR 83 Plate-forme Ingénierie des Protéines et Synthèse Peptidique, Paris, France

\begin{abstract}
Transcriptomic and peptidomic analysis of skin secretions from the Painted-belly leaf frog Phyllomedusa sauvagii led to the identification of 5 novel phylloseptins (PLS-S2 to -S6) and also of phylloseptin-1 (PSN-1, here renamed PLS-S1), the only member of this family previously isolated in this frog. Synthesis and characterization of these phylloseptins revealed differences in their antimicrobial activities. PLS-S1, -S2, and -S4 (79-95\% amino acid sequence identity; net charge $=+2)$ were highly potent and cidal against Gram-positive bacteria, including multidrug resistant $S$. aureus strains, and killed the promastigote stage of Leishmania infantum, L. braziliensis and L. major. By contrast, PLS-S3 (95\% amino acid identity with PLS-S2; net charge $=+1$ ) and -S5 (net charge $=+2$ ) were found to be almost inactive against bacteria and protozoa. PLS-S6 was not studied as this peptide was closely related to PLS-S1. Differential scanning calorimetry on anionic and zwitterionic multilamellar vesicles combined with circular dichroism spectroscopy and membrane permeabilization assays on bacterial cells indicated that PLS-S1,-S2, and -S4 are structured in an amphipathic $\alpha$-helix that disrupts the acyl chain packing of anionic lipid bilayers. As a result, regions of two coexisting phases could be formed, one phase rich in peptide and the other lipid-rich. After reaching a threshold peptide concentration, the disruption of lipid packing within the bilayer may lead to local cracks and disintegration of the microbial membrane. Differences in the net charge, $\alpha$-helical folding propensity, and/ or degree of amphipathicity between PLS-S1, -S2 and -S4, and between PLS-S3 and -S5 appear to be responsible for their marked differences in their antimicrobial activities. In addition to the detailed characterization of novel phylloseptins from $P$. sauvagii, our study provides additional data on the previously isolated PLS-S1 and on the mechanism of action of phylloseptins.
\end{abstract}

Citation: Raja Z, André S, Piesse C, Sereno D, Nicolas P, et al. (2013) Structure, Antimicrobial Activities and Mode of Interaction with Membranes of Bovel Phylloseptins from the Painted-Belly Leaf Frog, Phyllomedusa sauvagii. PLoS ONE 8(8): e70782. doi:10.1371/journal.pone.0070782

Editor: Hubert Vaudry, University of Rouen, France, France

Received April 13, 2013; Accepted June 21, 2013; Published August 13, 2013

Copyright: (c) 2013 Raja et al. This is an open-access article distributed under the terms of the Creative Commons Attribution License, which permits unrestricted use, distribution, and reproduction in any medium, provided the original author and source are credited.

Funding: The present work was supported by the UPMC, the Agence Nationale pour la Recherche (ANR-Prob DOM) and the DVS/AIRD (Direction de Ia Valorisation au Sud/Agence Inter-établissements de Recherche pour le Développement; AAP Leishmed 2010). Zahid Raja and Sonia André are PhD students at UPMC supported by a fellowship from the French Ministère de I'Enseignement Supérieur et de la Recherche, allocated by the Ecole Doctorale iViv (ED 387, UPMC, Paris, France). The funders had no role in study design, data collection and analysis, decision to publish, or preparation of the manuscript.

Competing Interests: The authors have declared that no competing interests exist.

*E-mail: ali.ladram@upmc.fr

9 These authors contributed equally to this work.

\section{Introduction}

The dermaseptin superfamily contains several families of host defense peptides that are synthetized in the skin of Hylidae frogs $[1,2,3]$. The peptides are small, 10 to 50 amino acid residues long, cationic, and act in different ways, although disrupting and permeabilizing the anionic bacterial cell membrane is the most frequent [4-7]. These peptide families include the dermaseptins (stricto sensu), the plasticins, the dermatoxins, the phylloxins, the phylloseptins, the raniseptins, the caerins, the caerin-related peptides, the hyposins, the fallaxidins, the frenatins, and the aureins. It has been speculated that the diversification of antimicrobial peptides within a species is part of an evolutionary strategy for providing frogs with the maximum protection against a wide range of microorganisms [3,8,9]. Thus, the impressive interspecies variations in the expression of skin antimicrobial peptides may be exploited for discovering new antimicrobial molecules targeting specific microorganisms for which the therapeutic armamentarium is scarce. In addition, the discovery of new peptides with novel structural and biochemical properties may also shed light on the exact roles of various parameters, such as net charge, percent of $\alpha$-helical/ $\beta$-sheet structure, and amphipathicity, on the ability of antimicrobial peptides to bind to and disrupt microbial membranes. Moreover, the strategy that the frogs have evolved over millions of years for the generation and design of an enormous array of small peptide antibiotics, each with high potency and specificity for particular microorganisms, may be adaptable for use in vitro.

The 16-19 amino acid residue phylloseptins (PLSs) are a new emerging family of cationic antimicrobial peptides that belong to the dermaseptin superfamily, and whose members have been isolated from various genera of the Phyllomedusinae subfamily 
Table 1. Primary structure of phylloseptins-S identified in the skin of $P$. sauvagii.

\begin{tabular}{llllll}
\hline & & & & & \\
\hline $\begin{array}{l}\text { Phyllo } \\
\text { septin }\end{array}$ & Sequence & $\begin{array}{l}\text { Net } \\
\text { charge }\end{array}$ & $<\mathbf{H}>$ & $<\mu \mathbf{H}>$ & Fraction \\
\hline PLS-S1 & FLSLIPHIVSGVASIAKHF & +2 & 0.81 & 0.55 & $54-56$ \\
PLS-S2 & FLSLIPHIVSGVASLAKHF $_{a}$ & +2 & 0.80 & 0.55 & $54-56$ \\
PLS-S3 & FLSLIPHIVSGVASLAIHF $_{a}$ & +1 & 0.95 & 0.43 & ND \\
PLS-S4 & FLSMIPHIVSGVAALAKHL $_{a}$ & +2 & 0.79 & 0.52 & 53 \\
PLS-S5 & LLGMIPVAISAISALSKL $_{a}$ & +2 & 0.85 & 0.35 & 62 \\
PLS-S6 & FLSLIPHIVSGVASIAKHL & +2 & 0.80 & 0.55 & ND \\
\hline
\end{tabular}

Identical amino acid residues are indicated in bold. a: amide; $<\mathrm{H}>$ :

Hydrophobicity; $\langle\mu \mathrm{H}>$ : Hydrophobic moment. The net charge $(\mathrm{pH} 7.4)$ and the original HPLC fraction are indicated. ND: not detected. The C-terminal

amidation of PLS-S3 and -S5 is based on the presence of the Gly residue (amide donor) at the C-terminus of the PLS precursor and on the fact that all members of the PLS family are amidated.

doi:10.1371/journal.pone.0070782.t001

(Agalychnis, Phasmahyla, and Phyllomedusa) [2,10-16]. Like the archetypal dermaseptins (sensu stricto), these peptides seem to occur in multiple paralogous forms in each species with small differences in amino acid composition. Although only a few of these peptides were properly tested against various microorganisms, significant differences in antimicrobial activities and target microorganism specificities have been observed between orthologous peptides, as well as paralogous peptides. For instance, PLS-H1 from Phyllomedusa hypochondrialis and phylloseptin-1 (PSN-1) from Phyllomedusa sauvagii (63\% amino acid sequence identity) exhibited marked differences in their potencies to inhibit the growth of Escherichia coli (minimal inhibitory concentration, MIC $=8 \mu \mathrm{M}$ and $80 \mu \mathrm{M}$, respectively) $[10,15]$, whereas PLS-H1 -H2, and -H3 (74\% sequence identity) demonstrated almost similar activities against Gram-negative and Gram-positive bacteria (MIC ranging from 2 to $8 \mu \mathrm{M})[10,17]$. PLS-L1 from Hylomantis lemur is highly potent against the Gram-positive bacteria Staphylococcus aureus $(\mathrm{MIC}=8 \mu \mathrm{M})$ [13], whereas PLS-L2 is only weakly active (MIC $=50 \mu \mathrm{M})$ but exhibit insulin-releasing activity [14]. Interestingly, some phylloseptins (PLS-H1; PLS-O1 and -O2 from Phyllomedusa oreades) demonstrated in vitro activity against the protozoan parasites Leishmania amazonensis promastigotes, Plasmodium falciparum (rings, trophozoites, and schizonts), and Trypanosoma cruzi (trypomastigotes) [10,18], making phylloseptins potential candidates for the treatment of malaria, leishmaniasis, and Chagas disease. The phylloseptins are Lys/His-rich antimicrobial peptides, most of them carrying 1 to 3 His residues that may lead to a variation of the effective net charge and biological activity at physiological and acidic $\mathrm{pHs}$, and can be predicted to adopt an amphipathic $\alpha$ helical structure in membrane-mimetic environment [17]. Although the mechanisms by which phylloseptins act against microbial cells are unknown, it is speculated that the cationic peptides first bind to the anionic microbial membrane surface and then adopt a helical amphipathic structure that promotes their insertion into the membrane, causing the collapse of the membrane at a critical peptide concentration.

In the present study, we have used the conservation of the preproregion sequences of the preprodermaseptin transcripts to identify and isolate five new members of the phylloseptin family (PLS-S2 to -S6) in the South American hylid frog Phyllomedusa sauvagii (subfamily: Phyllomedusinae), in addition to the previously isolated phylloseptin-1 (PSN-1, here renamed PLS-S1) [15] (Table 1). A detailed characterization of these synthetic phyllo- septins was undertaken, except for PLS-S6, a paralog with physicochemical properties identical to PLS-S1. Structure and activities were determined using circular dichroism and antimicrobial assays against various microorganisms, including Grampositive and Gram-negative bacteria, yeasts, and Leishmania parasites. To address the mechanism of action, we have used bacterial time-kill and permeabilization assays, and differential scanning calorimetry on multilamellar vesicles composed of anionic and zwitterionic lipids as models for prokaryotic and eukaryotic plasma membranes.

\section{Materials and Methods}

\section{Frog species}

Specimens of $P$. sauvagii were obtained from a commercial source (La Ferme Tropicale, Paris, France). Frogs were bred as previously described [19]. They were housed in large wooden cages $(120 \times 90 \times 90 \mathrm{~cm})$, covered on three sides by plastic mosquito netting. Phyllodendron, Potos, and Dracena were used as perches, and water bowls were provided for nocturnal bathing. The frogs were fed crickets. The protocol of animal handling and treatment was performed in accordance with the guidelines of the animal ethics committee of the French Ministry of Agriculture, Veterinary Department for Animal Health and Protection, under the supervision of authorized investigators (agreement N I75UPMC-F1-07). Our study does not involve in vivo experiments and animal suffering.

\section{Cloning of $P$. sauvagii phylloseptin cDNA precursors}

Skin secretions of one adult specimen of $P$. sauvagii were collected by gentle squeezing of the latero-dorsal portion of the skin of the living frog, as previously described [19] and dilution in $1 \mathrm{ml}$ sterile diethylpyrocarbonate (DEPC)- $\mathrm{H}_{2} \mathrm{O}$. The solution was rapidly frozen in liquid nitrogen and lyophilized. Poly $(\mathrm{A})^{+} \mathrm{RNA}$ was isolated from the dry material $(5 \mathrm{mg}$ ) using the MicroFastTrack mRNA isolation kit (Invitrogen) and transcribed into cDNAs with an oligo(dT) primer (Advantage RT-for-PCR kit, Clontech) according to the protocol of the manufacturers. PCR was performed using a set of specific primers (5'-TGACCTTCAGTACGCAGCACTTTC-3' / 5'-GTGGTACATAATTGATAATTGTGCT- $3^{\prime}$ ) matching the conserved $5^{\prime}$ - and $3^{\prime}$-UTR of preprodermaseptins, respectively. The following cycling procedure was used: initial denaturation, $2 \mathrm{~min}$ at $94^{\circ} \mathrm{C} ; 30$ cycles of $45 \mathrm{~s}$ at $94^{\circ} \mathrm{C}, 1 \mathrm{~min}$ at $49^{\circ} \mathrm{C}, 3 \mathrm{~min}$ at $72^{\circ} \mathrm{C}$; final extension, $10 \mathrm{~min}$ at $72^{\circ} \mathrm{C}$. PCR products were gel purified (NucleoSpin Extract, Macherey-Nagel), cloned into the pGEM-T easy vector system (Promega) and sequenced (Beckman Coulter Genomics SA). The nucleotide sequences of pre-prophylloseptins (ppPLSs) described in this study have been deposited in the EMBL Nucleotide Sequence Database under the accession numbers AM903077 (ppPLS-S1), AM903078 (ppPLS-S2), AM903079 (ppPLS-S3), AM903080 (ppPLS-S4), AM903081 (ppPLS-S5), HE974361 (ppPLS-S6).

\section{Identification of mature phylloseptins in the skin extract of $P$. sauvagii}

$80 \mathrm{mg}$ of a frozen acidic lyophilized extract of $P$. sauvagii skin secretions were obtained according to a previous described protocol [20] and were prepurified on a Sep-Pak C-18 cartridge eluted with $70 \%$ acetonitrile (ACN) in $0.1 \%$ trifluoroacetic acid (TFA) $/ \mathrm{H}_{2} \mathrm{O}$. The prepurified extract $(7 \mathrm{mg})$ was lyophilized, reconstituted in $0.1 \%$ TFA $/ \mathrm{H}_{2} \mathrm{O}$ and fractionated by reversedphase high performance liquid chromatography (RP-HPLC) on a semi-preparative Nucleosil C-18 column $(5 \mu \mathrm{m}, 250 \times 10 \mathrm{~mm}$, Interchim) eluted at $4 \mathrm{~mL} / \mathrm{min}$ with a $0-70 \%$ linear gradient of 
Table 2. Antimicrobial activity of phylloseptins-S.

\begin{tabular}{|c|c|c|c|c|c|}
\hline & PLS-S1 & PLS-S2 & PLS-S3 & PLS-S4 & PLS-S5 \\
\hline & & & \multicolumn{3}{|l|}{ MIC $(\mu \mathrm{M})$} \\
\hline \multicolumn{6}{|l|}{ Gram-positive bacteria } \\
\hline S. aureus ATCC 25923 & 6.25 & 6.25 & $>200$ & 6.25 & 25 \\
\hline S. aureus ST1065 & 6.25 & 6.25 & $>200$ & 6.25 & $>100$ \\
\hline S. aureus ATCC $43300^{\mathrm{a}}$ & 6.25 & 6.25 & $>200$ & 6.25 & $>100$ \\
\hline S. aureus ATCC BAA- $44^{\mathrm{b}}$ & 6.25 & 6.25 & $>200$ & 6.25 & $>100$ \\
\hline E. faecalis ATCC 29212 & 25 & 25 & $>200$ & 50 & 100 \\
\hline S. pyogenes ATCC 19615 & 3.12 & 1.56 & 12.5 & 3.12 & ND \\
\hline \multicolumn{6}{|l|}{ Gram-negative bacteria } \\
\hline E. coli ATCC 25922 & 70 & 25 & $>200$ & 25 & $>100$ \\
\hline E. coli ML-35p & $>100$ & 30 & $>200$ & 25 & $>100$ \\
\hline P. aeruginosa ATCC 27853 & $>100$ & 200 & $>200$ & 100 & $>100$ \\
\hline A. baumannii ATCC 19606 & 6.25 & 6.25 & $>200$ & 6.25 & ND \\
\hline K. pneumoniae ATCC 13883 & $>100$ & 25 & $>200$ & 25 & ND \\
\hline \multicolumn{6}{|l|}{ Yeasts } \\
\hline C. parapsilosis ATCC 22019 & 100 & 50 & $>200$ & 50 & $>100$ \\
\hline \multirow[t]{2}{*}{ S. cerevisiae } & 12.5 & 6.25 & $>200$ & 12.5 & ND \\
\hline & & & $\mathrm{IC}_{50}(\mu \mathrm{M})$ & & \\
\hline \multicolumn{6}{|l|}{ Leishmania promastigotes } \\
\hline L. infantum & 16.5 & 18.5 & NA & 22.0 & NA \\
\hline L. major & 12.6 & 13.3 & NA & 18.0 & NA \\
\hline L. braziliensis & 15.3 & 15.0 & NA & 17.2 & NA \\
\hline
\end{tabular}

${ }^{a}$ Resistant to methicillin and oxacillin. ${ }^{b}$ Resistant to amoxicillin/clavulanic acid, cephalothin, ciprofloxacin, erythromycin, gentamicin, imipenem, oxacillin, penicillin, tetracycline, ampicillin, doxycycline, methicillin, azithromycin, ceftriaxone, clindamycin, lincomycin, perfloxacin, rifampin, and tobramycin. ND: not determined. NA: not active as it was not possible to reach $I C_{50}$ at the highest concentration tested $(60 \mu \mathrm{M})$. MICs and IC 50 are expressed as average values from three independent experiments performed in triplicates. $\mathrm{IC}_{50}$ values were determined from a dose-response inhibition fit using GraphPad Prism 5.0.

doi:10.1371/journal.pone.0070782.t002

acetonitrile in $0.1 \%$ TFA/water $(1 \%$ ACN/min). Fractions corresponding to $4 \mathrm{~mL}$ were collected and analyzed by MALDITOF-MS (Voyager DE-PRO Applied Biosystems) using the matrix $\alpha$-cyano-4-hydroxycinnamic acid. The MS positive ion spectra were carried out in the reflector mode with external calibration using the 4700 Standard kit. The primary structure of mature PLSs was confirmed by MALDI-TOF-TOF (4700 Proteomic Analyzer, Applied Biosystems). The protonated molecule of the precursor was selected in the window $(-5 u,+5 u)$ and fragmented using $\mathrm{N}_{2}$ as the collision gas $\left(2 \times 10^{-7}\right.$ Torr, collision energy $1 \mathrm{keV}$ ).

\section{Solid phase peptide synthesis}

Carboxamidated phylloseptins (PLS-S1, -S2, -S3, -S4 and -S5) were synthesized using solid-phase FastMoc chemistry procedure on an Applied Biosystems 433A automated peptide synthesizer as described [20]. Resin and Fmoc-protected amino acids were purchased from Iris Biotech GMBH, and solvents from Carlo Erba. Briefly, carboxamidated peptides were prepared on a 4methylbenzhydrylamine polystyrene resin (Rink Amide MBHA PS resin) substituted at $0.81 \mathrm{mmol} / \mathrm{g}$. Activation $(30 \mathrm{~min})$ of Fmoc amino acids (10 molar excess) was realized with 2-(1H-b enzotriazol-1-yl)-1,1,3,3-tetramethyluronium hexafluorophosphate (0.5 M HBTU solubilized in dimethylformamide) and diisopropylethylamine $(2 \mathrm{M})$ in $\mathrm{N}$-methylpyrrolidone (NMP). N-Fmoc protecting groups were removed with $20 \%$ piperidine in NMP. A systematic double-coupling protocol was used followed by a capping step with acetic anhydride performed at the end of each cycle. The peptidyl resin was cleaved and deprotected by incubation with an acidic cocktail (95\% TFA, 2.5\% triisopropylsilane, $2.5 \%$ water) for $3 \mathrm{~h}$ at room temperature (for PLS-S4 and S5 containing a Met residue: 94\% TFA, 1\% triisopropylsilane, $2.5 \%$ ethanedithiol, $2.5 \%$ water). The resin was removed by filtering the resulting mixture, and the crude peptides were precipitated with methyl-tert-butyl ether (MTBE) at $4^{\circ} \mathrm{C}$. They were recovered by centrifugation $\left(3,000 \times \mathrm{g}, 15 \mathrm{~min}, 4^{\circ} \mathrm{G}\right)$, washed 3 times with cold MTBE, dried under a stream of nitrogen, dissolved in 10\% acetic acid, and lyophilized. The lyophilized crude peptides were purified by RP-HPLC on a Phenomenex Luna ${ }^{\circledR}$ C18(2) semi-preparative column $(10 \mu \mathrm{m}, 250 \times 10 \mathrm{~mm})$ eluted at a flow rate of $5 \mathrm{~mL} / \mathrm{min}$ by a $20-70 \%$ linear gradient of ACN $(0.07 \% \mathrm{TFA})$ in $0.1 \% \mathrm{TFA} /$ water $(1 \% \mathrm{ACN} / \mathrm{min})$. The homogeneity and identity of the synthetic peptide were assessed by matrix-assisted laser desorption/ionization-time of flight (MALDITOF) mass spectrometry (Voyager DE-PRO Applied Biosystems) and RP-HPLC on a C18 analytical column (modulocart QS uptisphere $5 \mathrm{ODB}, 5 \mathrm{~mm}, 250 \times 4.6 \mathrm{~mm}$, Interchim) using the above conditions with a flow rate of $0.75 \mathrm{~mL} / \mathrm{min}$.

\section{Circular dichroism spectroscopy}

The far-ultraviolet circular dichroism (CD) spectra were recorded as described [20]. Phylloseptins-S (30 $\mu \mathrm{M})$ were solubi- 
ppPLS-S1

tgaccttcagtacccagcactttctgacttacaagaccaaacATGGCTTTCTTGAAGAAA 60

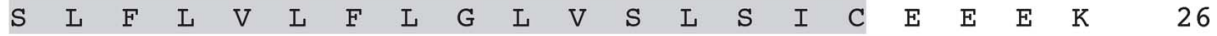
TCTCTTTTCCTTGTACTATTCCTTGGACTGGTTTCTCTTTCCATCTGTGAAGAAGAGAAA 120

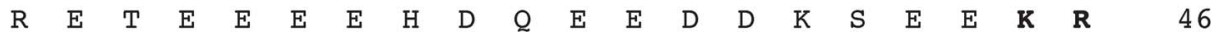
AGAGAGACTGAAGAGGAAGAACATGATCAAGAgGAAGATGATAAAAGTGAAGAGAAGAGA 180

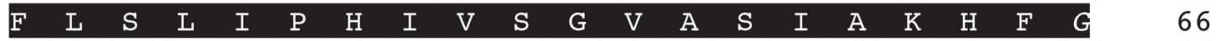
TTCCTCAGCTTGATACCACATATAGTATCTGGAGTAGCTTCAATTGCTAAACATTTCGGT 240

TAAtacalgtaacatttcttaactctaaggagcacaattatcaattatgtaccac $\quad 296$

\section{ppPLS-S2}

$\begin{array}{llllllll}M & A & F & L & K & K & 6\end{array}$

tgaccttcagtacccagcactttctgacttacaagaccaaacATGGCTTTCTTGAAGAAA 60 $\begin{array}{llllllllllllllllllllll}S & L & F & L & V & L & F & L & G & L & V & S & L & S & I & C & E & E & E & K & & 26\end{array}$ TCTCTTTTCCTTGTGCTATTCCTTGGACTGGTTTCCCTTTCCATCTGTGAAGAAGAGAAA 120 $\begin{array}{llllllllllllllllllllll}R & E & T & E & E & E & E & H & D & Q & E & E & D & D & K & S & E & E & K & R & & 46\end{array}$ AGAGAGACTGAAGAGGAAGAACATGATCAAGAGGAAGATGATAAAAGTGAAGAGAAGAGA 180

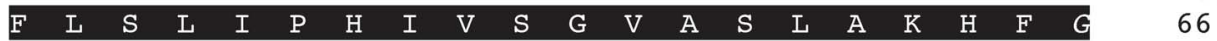
TTCCTCAGCTTGATACCACATATAGTATCTGGAGTAGCTTCACTTGCTAAACATTTCGGT 240 TAAtacaatgtaacatttcttaactctaaggagcacaattatcaattatgtaccac $\quad 296$

\section{ppPLS-S3}

tgaccttcagtacccagcacttetgacttacaagaccaaacATGGCTTTCTTGAAGAAA $\begin{array}{lllllllllllllllllllllll}S & L & F & L & V & L & F & L & G & L & V & S & L & S & I & C & E & E & E & K & & 26\end{array}$ TCTCTTTTCCTTGTGCTATTCCTTGGACTGGTTTCCCTTTCCATCTGTGAAGAAGAGAAA 120

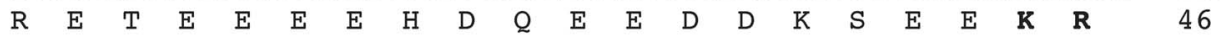
AGAGAGACTGAAGAGGAAGAACATGATCAAGAGGAAGATGATAAAAGTGAAGAGAAGAGA 180 \begin{tabular}{llllllllllllllllllllll}
\hline & L & S & I & I & P & H & I & V & S & G & V & A & S & I & A & I & H & F & $G$ & & 66
\end{tabular} TTCCTCAGCTTGATACCACATATAGTATCTGGAGTAGCTTCACTTGCTATACATTTCGGT 240 TAAtacaatgtaacatttcttaactctaaggagcacaattatcaattatgtaccac $\quad 296$

ppPLS-S4

tgaccttcagtacccagcactt $S$ I $T$ T TCTCTTTTCCTTGTACTATTCCTTGGACTGGTTTCCCTTTCCATCTGTGAAGAAGAGAAA 120 $\begin{array}{lllllllllllllllllllll}R & E & T & E & E & E & E & H & D & Q & E & E & D & D & K & S & E & E & K & R & \end{array}$ AGAGAGACTGAAGAGGAAGAACATGATCAAGAGGAAGATGATAAAAGTGAAGAGAAGAGA 180

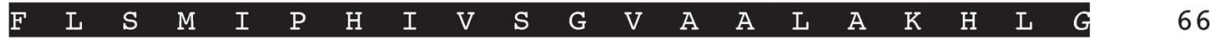
TTCCTCAGCATGATACCACATATAGTATCTGGAGTAGCTGCACTTGCTAAACATTTAGGT 240

TAAtacaatgtaacatttcttaactctaaggagcacaattatcaattatgtaccac

\section{ppPLS-S5}

$\begin{array}{cccccc}M & S & F & L & K & K \\ \text { tgaccttcagtacccagcacttetgaattacaagaccaaatATGTCTTCCTCAAGAAA }\end{array}$

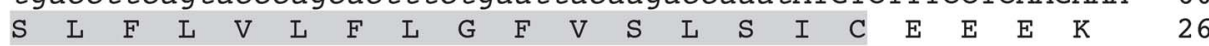
TCTCTTTTCCTTGTACTTTTCCTTGGATTTGTTTCCCTTTCAATCTGTGAAGAAGAGAAA 120 $\begin{array}{llllllllllllllllllllll}R & E & T & E & E & K & E & N & E & Q & E & D & D & R & E & E & R & S & E & E & & 46\end{array}$ AGAGAGACTGAAGAGAAAGAAAATGAGCAAGAGGACGACCGTGAAGAGCGAAGTGAAGAG 180

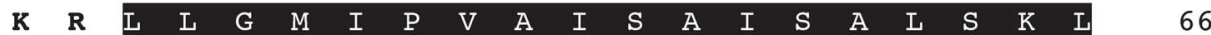
AAGAGATTATTAGGCATGATTCCAGTGGCAATATCTGCAATATCTGCACTTTCAAAATTA 240 G

GGTTAAtagaatgtaacattttataactctaaggagcacaattatcaattatgtaccac

\section{ppPLS-S6}

tgaccttcagtacccagcactttctgacttacaagaccaaacATGGCTMTCTCAAGAAA

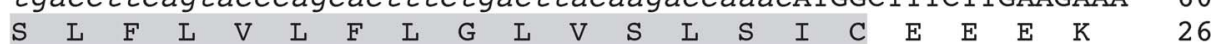
TCTCTTTTCCTTGTACTATTCCTTGGACTGGTTTCTCTTTCCATCTGTGAAGAAGAGAAA 120 $\begin{array}{llllllllllllllllllllll}R & E & T & E & E & E & E & H & D & Q & E & E & D & D & K & S & E & E & K & R & & 46\end{array}$ AGAGAGACTGAAGAGGAAGAACATGATCAAGAGGAAGATGATAAAAGTGAAGAGAAGAGA 180

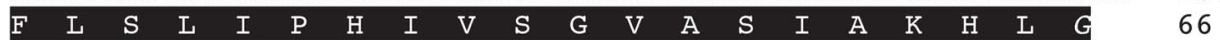
TTCCTCAGCTTGATACCACATATAGTATCTGGAGTAGCTTCAATTGCTAAACATTTAGGT 240 TAAtacaatgtaacatttcttaactctaaggagcacaattatcaattatgtaccac $\quad 296$ 
Figure 1. Complete nucleotide and deduced amino acid sequences of the CDNAs encoding $P$. sauvagii preprophylloseptin-S1 (ppPLS-S1, EMBL accession number: AM903077), -S2 (ppPLS-S2, AM903078), -S3 (ppPLS-S3, AM903079), -S4 (ppPLS-S4, AM903080), -S5 (ppPLS-S5, AM903081), and -S6 (ppPLS-S6, HE974361). The open reading frames (capital letters) contain the signal peptide (gray), followed by an acidic sequence ending with a pair of basic residues (in bold), and the phylloseptin progenitor sequence (black). The $\mathrm{G}$ residue (in italic) at the C-terminal of the progenitor sequence serves as an amide donor. The stop codon is indicated in bold. The partial 5'- and 3'UTR are represented in italics and lowercase.

doi:10.1371/journal.pone.0070782.g001

lized either in $80 \mathrm{mM}$ sodium dodecyl sulfate (SDS) or in phosphate-buffered saline (PBS: $10 \mathrm{mM}$ phosphate, $\mathrm{pH} 7.3$ ) containing $1 \mathrm{mg} / \mathrm{mL}$ of large unilamellar vesicles (LUVs) of 1,2dimyristoyl-sn-glycero-3-phosphocholine (DMPC) and 1,2-dimyristoyl-sn-glycero-3-phosphoglycerol (DMPG) $\quad(3: 1 \mathrm{~mol} / \mathrm{mol})$. DMPG and DMPG were purchased from Avanti Polar Lipids, Inc. Each spectrum was the average of four scans. CD measurements are reported as $\Delta / \mathrm{n}$, where $\Delta$ is the dichroic increment and $\mathrm{n}$ is the number of residues in the peptide.

\section{Antimicrobial activities}

The effect of phylloseptins-S was evaluated against several bacterial strains and yeasts (Table 2). Bacteria were cultured in Luria-Bertani broth (LB), whereas yeasts were cultured in Yeast
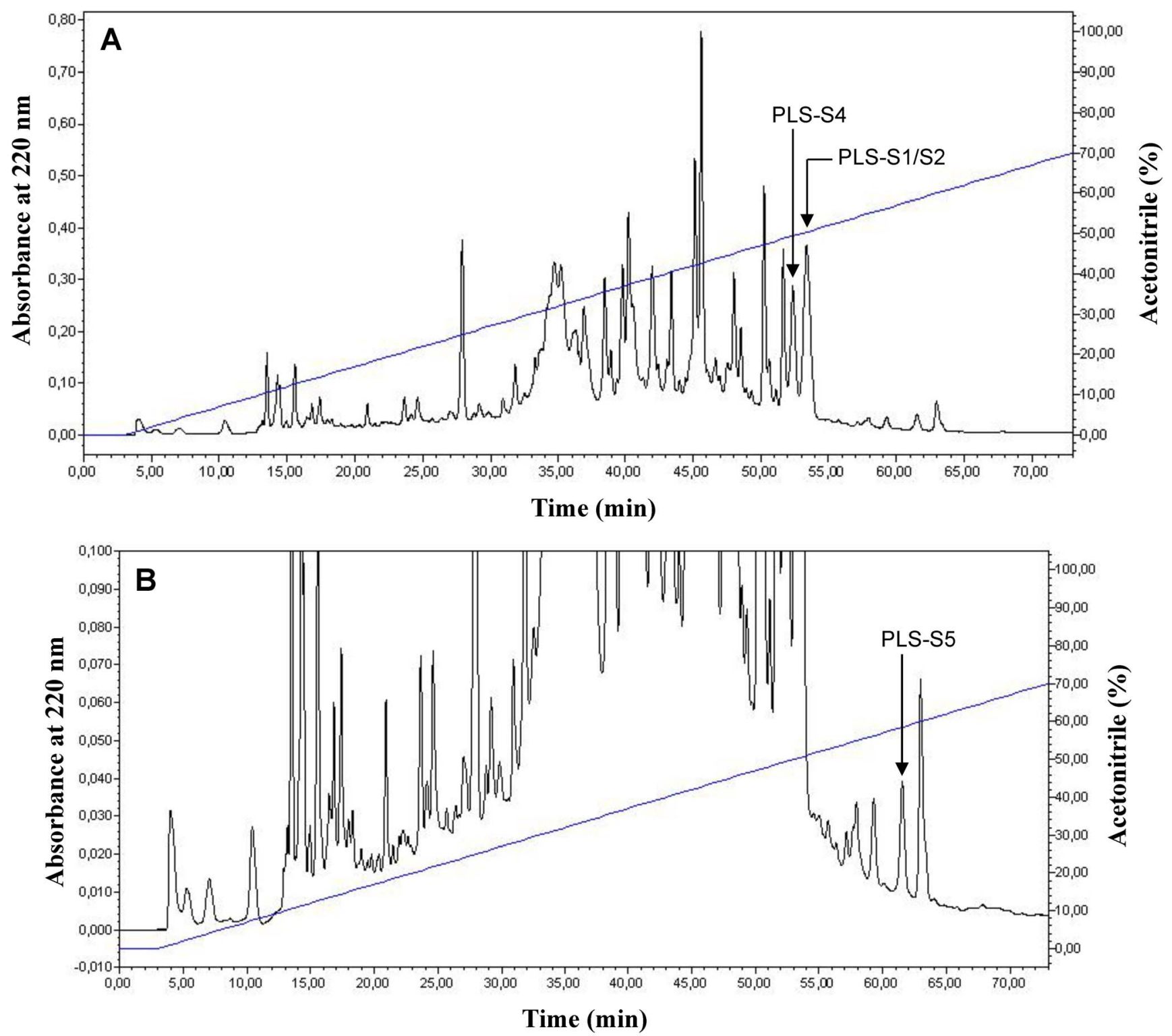

Figure 2. Reversed-phase HPLC chromatogram of $P$. sauvagii skin extract prepurified on a sep-pak C18 cartridge (A, full scale; B, zoom). The sample was injected on a semi-preparative Nucleosil C18 column eluted at $4 \mathrm{~mL} / \mathrm{min}$ with a $0-70 \%$ linear gradient of acetonitrile in $0.1 \%$ TFA/water ( $1 \% \mathrm{ACN} / \mathrm{min})$. Fractions of $4 \mathrm{~mL}$ were collected, lyophilized, and analyzed. The position of the mature PLSs is indicated by an arrow (PLSS3 and PLS-S6 were not detected). The identification of PLSs was achieved by MALDI-TOF-MS and MS/MS (Supporting information, Fig. S1 A-C and S2 A-C).

doi:10.1371/journal.pone.0070782.g002 


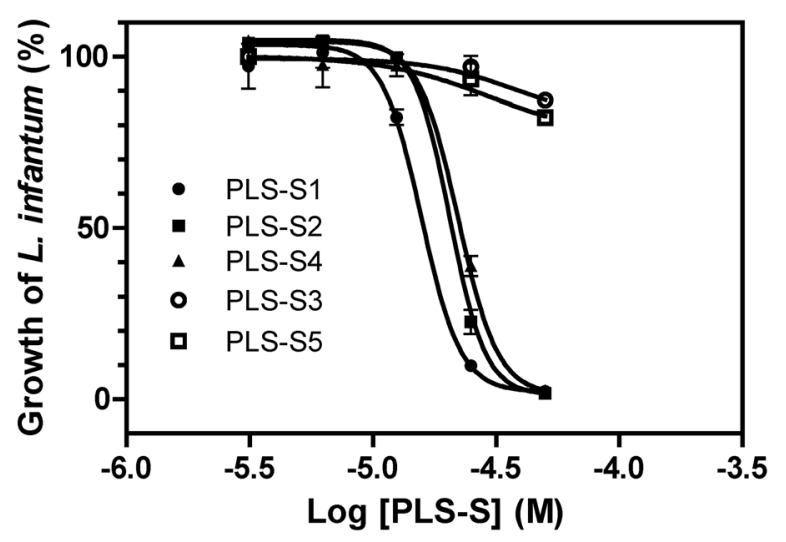

Figure 3. Activity of phylloseptins-S against Leishmania infantum promastigotes. $\mathrm{IC}_{50}$ values were determined from a doseresponse inhibition fit using GraphPad Prism 5.0 (Table 2). Results represent the mean \pm S.E.M. and are representative of three experiments carried out in triplicates.

doi:10.1371/journal.pone.0070782.g003

Peptone Dextrose medium (YPD), and minimal inhibitory concentrations (MICs) were determined by measuring the absorbance at $630 \mathrm{~nm}$ in 96-well microtitration plates, as described previously [21]. Leishmanicidal activity of phylloseptins-S was also examined against promastigotes of different Leishmania species: Leishmania infantum (strain MHOM/MA/67/ ITMAP-263), L. major (MHOM/SU/73/5-ASKH) and L. braziliensis (MHOM/BR/75/M2904). Culture of promastigotes and determination of the growth inhibition were performed as previously described $[20,22,23]$.

\section{Cytotoxic activities}

Hemolytic assays were performed using fresh human erythrocytes from a healthy donor according to a previously described protocol [20]. Cytotoxic activity of PLS-S was also determined on the human leukemia monocyte cell line THP-1. $80 \mu \mathrm{L}$ of $6.25 \times 10^{5}$ cells $/ \mathrm{mL}$ were incubated for $72 \mathrm{~h}$ with $20 \mu \mathrm{L}$ of peptide (3 to $50 \mu \mathrm{M}$, final concentrations) at $37^{\circ} \mathrm{C}$ and $5 \% \mathrm{CO}_{2}$ in RPMI medium supplemented with $10 \%$ FCS. The cell viability was determined by adding $10 \mu \mathrm{L}$ of methylthiazolyldiphenyl-tetrazolium bromide (MTT, $10 \mathrm{mg} / \mathrm{mL}$ ) to the plate. After $4 \mathrm{~h}$ incubation at $37^{\circ} \mathrm{C}$, formazan was solubilized with $100 \mu \mathrm{L}$ of a solution containing 50\% isopropanol and 10\% SDS, and the absorbance was measured at $570 \mathrm{~nm}$. The lytic concentration $50\left(\mathrm{LC}_{50}\right)$, which correspond to the peptide concentration producing $50 \%$ lysis, was determined with the GraphPad Prism ${ }^{\circledR} 5.0$ software. Results were expressed as the mean of three independent experiments performed in triplicates.

\section{Time-kill assays}

The time-kill kinetics of phylloseptins-S against the Gramnegative bacteria E. coli ML-35p and the Gram-positive strain $S$. aureus ST1065 were evaluated as previously described [20] with a dose of peptide corresponding to the MIC and two-fold above the MIC. Two experiments were realized in triplicates.

Permeabilization of the cytoplasmic membrane of Grampositive (S. aureus ST1065) and Gram-negative (E. coli ML35p) bacteria

PLS-induced permeabilization of the cytoplasmic plasma membranes of E. coli ML-35p and S. aureus ST1065 was measured
Table 3. Cytotoxic activity of phylloseptins-S.

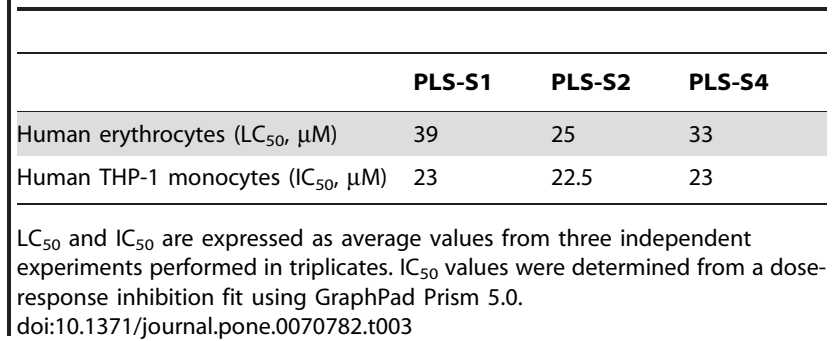

by the rate of production of 0 -nitrophenol (ONP) at $405 \mathrm{~nm}$, following hydrolysis of o-nitrophenyl $\beta$-D-galactopyranoside (ONPG) by $\beta$-galactosidase [24]. Dermaseptin B2 $(10 \mu \mathrm{M})$ [6] and PBS were used as positive and negative controls, respectively.

Study of the interactions of phylloseptins-S with vesicular model membranes by differential scanning calorimetry

Differential scanning calorimetry (DSC) experiments were performed using DMPC and DMPG (Avanti Polar Lipids, Inc.) multilamellar vesicles $(\mathrm{MLVs})$ according to the procedure previously described [25]. Twenty scans were run for each sample, with 10 min equilibration time between each scan. Thermodynamic values (Tm and $\Delta \mathrm{H})$ were estimated with the CpCalc software.

\section{Molecular dynamic simulations}

The docking studies of PLS-S2 with E. coli membrane model were carried out using Hex 6.3 protein docking software with a scoring function based on shape complementarities and electrostatic potentials. File for $E$. coli cytoplasmic membrane [26] was accessed from Department of Chemical and Biomolecular Engineering, Maryland, website (http://terpconnect.umd.edu/ jbklauda/research/download.html). Structural files for linear and $\alpha$-helical peptides were built with the Avogadro software 1.1.0. The structures were minimized using the conjugate gradient method and then were used for docking. For the non-structured peptide, a molecular dynamic simulation during $1 \mathrm{~ns}$ was performed on Abalone 1.8.53 using a flexible simple point-charge (SPG) water model [27]. The 3D model structures were visualized using Rasmol 2.7.5.2 software.

\section{Results}

CDNA cloning of phylloseptins-S from $P$. sauvagii

RT-PGR experiments were performed using Phyllomedusa sauvagii skin exudate mRNA as template and specific oligonucleotides designed to the conserved region $\left(5^{\prime}-\right.$ and $3^{\prime}$-UTR) of previously cloned precursors of the dermaseptin superfamily. A 300-bp amplified fragment was obtained and revealed after cloning and sequencing six different full-ORF phylloseptin precursor cDNAs encoding 66-67 residue sequences starting with a Met codon and ending with a stop codon (Fig. 1). All the deduced amino acid sequences contain a 22-residue signal peptide followed by a 24-26-residue acidic propiece with a pair of basic residues (Lys-Arg) at its C-terminus. A single copy of the mature PLS progenitor sequence is found at the extreme C-terminus of the precursors flanking the acidic propiece. One of these cDNAs encodes phylloseptin-1 (PSN-1) [15] that we have renamed PLSS1 (Table 1) in accordance with the established nomenclature [28]. The remaining five cDNAs correspond to novel phylloseptins-S and were designated as PLS-S2, -S3, -S4, -S5 and -S6 (Table 1). All these PLS-S precursors had the characteristic signature of the preproforms of the dermaseptin superfamily, i.e. a 

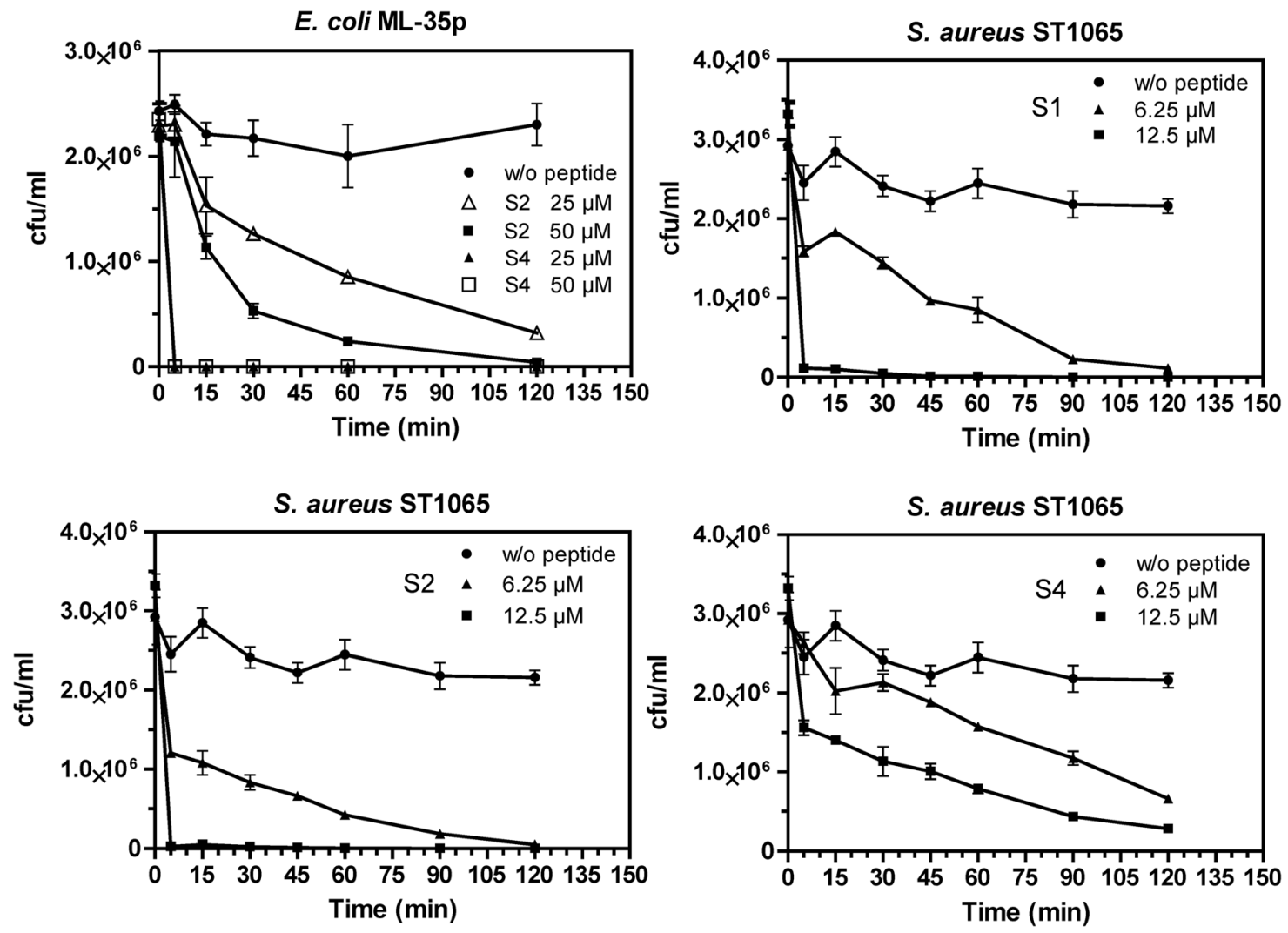

Figure 4. Time-kill curves of PLS-S1 (S1), -S2 (S2), and -S4 (S4). Bacteria (E. coli ML-35p and S. aureus ST1065, $\sim 2-310^{6} \mathrm{cfu} / \mathrm{mL}$ ) were diluted in PBS and incubated with synthetic PLSs at concentrations corresponding to the MIC (E. coli ML-35p: $25 \mu \mathrm{M}$, S. aureus ST1065: 6.25 $\mu \mathrm{M}$ ) and two-fold above the MIC. Controls correspond to bacteria incubated in PBS without peptide. The data are the means \pm S.E.M. of two experiments carried out in triplicates.

doi:10.1371/journal.pone.0070782.g004

signal peptide ending with a Cys residue, an acidic propiece with a typical prohormone processing signal Lys-Arg at the C-terminus, and a single downstream copy of the mature peptide progenitor sequence. The PLS-S precursors end with a Gly residue that serves as an amide donor for the C-terminal residue of the mature PLS (see below).

\section{Purification and identification of phylloseptins-S in the} skin of $P$. sauvagii

Extracts from the skin of $P$. sauvagii were analyzed by reversedphase HPLC to assess the presence of the predicted mature PLSs and the status of their $\mathrm{G}$ terminus in vivo (Fig. 2). Peptides with molecular masses matching those of PLS-S1, -S2, -S4, and -S5 were found by MALDI-TOF mass spectrometry (MALDI-TOF MS) (Fig. S1 A-C). The primary structure of the corresponding peptides (Table 1) was established by MALDI-TOF-TOF MS/MS from collision-induced dissociation of the parent ion and confirmed by the presence of the two-fragmentation series $\mathrm{b}$ and $\mathrm{y}$ and their amino acid sequences (Fig. S2 A-C). For each PLS-S, the sequence was obtained with remaining leucine/isoleucine indeterminations. PLS-S3 and -S6 were not detected probably due to their non-desorption or their presence in very small amount.

\section{Antimicrobial and cytotoxic activities of phylloseptins-S}

The antimicrobial activity of synthetic PLS-S1 to -S5 was assayed in LB medium ( $\mathrm{pH} 7)$ against several Gram-negative and Gram-positive bacteria, and multi-drug resistant $S$. aureus strains. As PLS-S6 is an analog of PLS-S1 (Leu instead of Phe at the C- terminus) with identical physicochemical properties (Table 1) and was not detected in HPLC fractions, the activity of this peptide was not evaluated. As indicated in Table 2, despite their paralogous relationships, the spectra of action of PLSs differ considerably. PLS-S1, -S2, and -S4 were highly active against Gram-positive bacteria with $\mathrm{MIC}$ in the range $1.56-6.25 \mu \mathrm{M}$, except E. faecalis for which a moderate (PLS-S1 and -S2, MIC $=25 \mu \mathrm{M})$ or low $(\mathrm{PLS}-\mathrm{S} 4, \mathrm{MIC}=50 \mu \mathrm{M})$ activity was observed. However, PLS-S1, -S2, and -S4 were less potent or devoid of activity against Gram-negative bacteria $(\mathrm{MIC}=25-30 \mu \mathrm{M})$ and yeasts (MIC $=50-100 \mu \mathrm{M}$ ), except $A$. baumannii and $S$. cerevisiae for which a potent activity $(\mathrm{MIC}=6.25-12.5 \mu \mathrm{M})$ was observed. The dose-response profiles showed sharp curves in which inhibition of 0-100\% was generated within a 1-2-fold peptide dilution (not shown). No visible colony was observed when MIC well contents (S. aureus ATCC 25923 and E. coli ATCC 25922) were spread on agar plates $\left(37^{\circ} \mathrm{C}\right.$, overnight), indicating that the peptides were bactericidal. The antiparasitic activity of PLSs was also determined against three Leishmania species (L. infantum, L. major, and $L$. braziliensis). As indicated in Table 2 and Fig. 3, PLS-S1, -S2 and S4 were highly potent against Leishmania species $\left(\mathrm{IC}_{50}=13-\right.$ $22 \mu \mathrm{M})$. PLS-1, -S2 and -S4 have moderate hemolytic activities with a $\mathrm{LC}_{50}(25-40 \mu \mathrm{M})$ above the MIC values determined for most of the sensitive Gram-positive bacterial strains tested, but were toxic for human monocytes THP-1 $\left(\mathrm{LC}_{50}=23 \mu \mathrm{M}\right)$ at leishmanicidal concentrations $(12-22 \mu \mathrm{M})$ (Table 3). PLS-S3 and S5 were inactive against most of the bacteria and protozoa tested, except $S$. pyogenes (PLS-S3, MIC $=12.5 \mu \mathrm{M}$ ) and $S$. aureus ATCG 


\section{S. aureus ST1065}
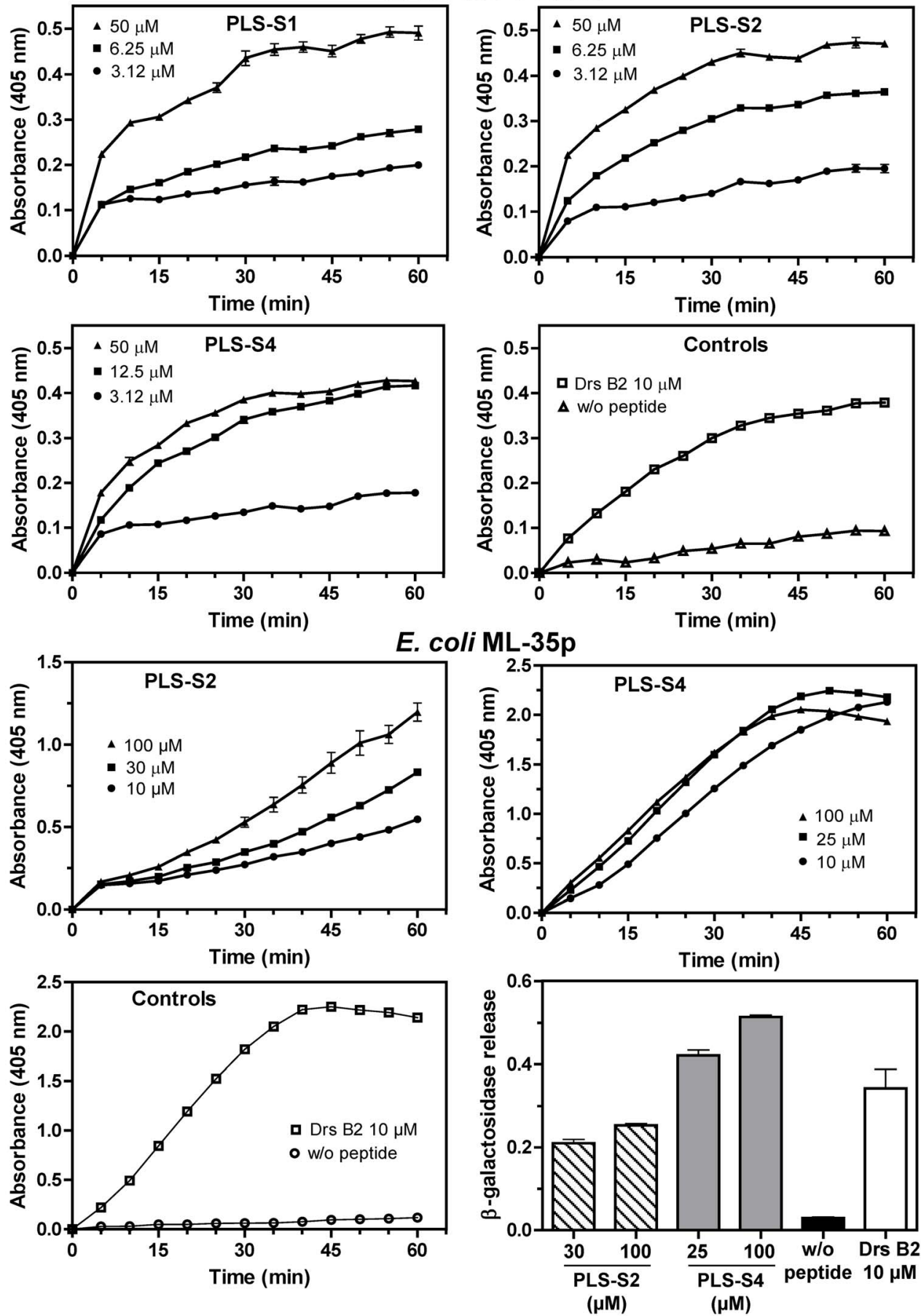

Figure 5. Kinetics of the cytoplasmic membrane leakage of $E$. coli ML-35p and S. aureus ST1065 after incubation with different concentrations of active phylloseptins-S. The membrane leakage was determined by measuring the production of o-nitrophenol at $405 \mathrm{~nm}$ following hydrolysis of ONPG by the cytoplasmic bacterial $\beta$-galactosidase. Data are expressed as the mean \pm S.E.M of two experiments carried out in triplicates after subtraction of the negative control values (w/o peptide) from the test values. Control panels display the kinetics obtained without peptide (negative control) and with $10 \mu \mathrm{M}$ dermaseptin B2 (Drs B2, positive control). For E. coli ML-35p, the extracellular release of $\beta$-galactosidase was also measured as the production of o-nitrophenol at $405 \mathrm{~nm}$ after incubation $(60 \mathrm{~min})$ of E. coli cells with PLS-S2 (30 and $100 \mu \mathrm{M})$ and PLS-S4 (25 and $100 \mu \mathrm{M}$ ), removing of bacteria by centrifugation and adding ONPG to the supernatant. The negative (w/o peptide) and positive (10 $\mu \mathrm{M}$ Drs B2) controls are indicated for comparison. Results are expressed as the mean \pm S.E.M of one representative experiment performed in triplicates. doi:10.1371/journal.pone.0070782.g005

25923 (PLS-S5, MIC $=25 \mu \mathrm{M}$ ) (Table 2). Because PLS-S3 contains histidines as basic residues and that approximately only $11 \%$ of these residues are positively charged at $\mathrm{pH} 7$, we have evaluated the antibacterial activity at $\mathrm{pH} 5$ at which His residues are predominantly positively charged $(\sim 91 \%)$. Interestingly, PLS$\mathrm{S} 3$ was found to be active $(\mathrm{MIC}=50 \mu \mathrm{M})$ against $E$. coli $\mathrm{ATCC}$ 

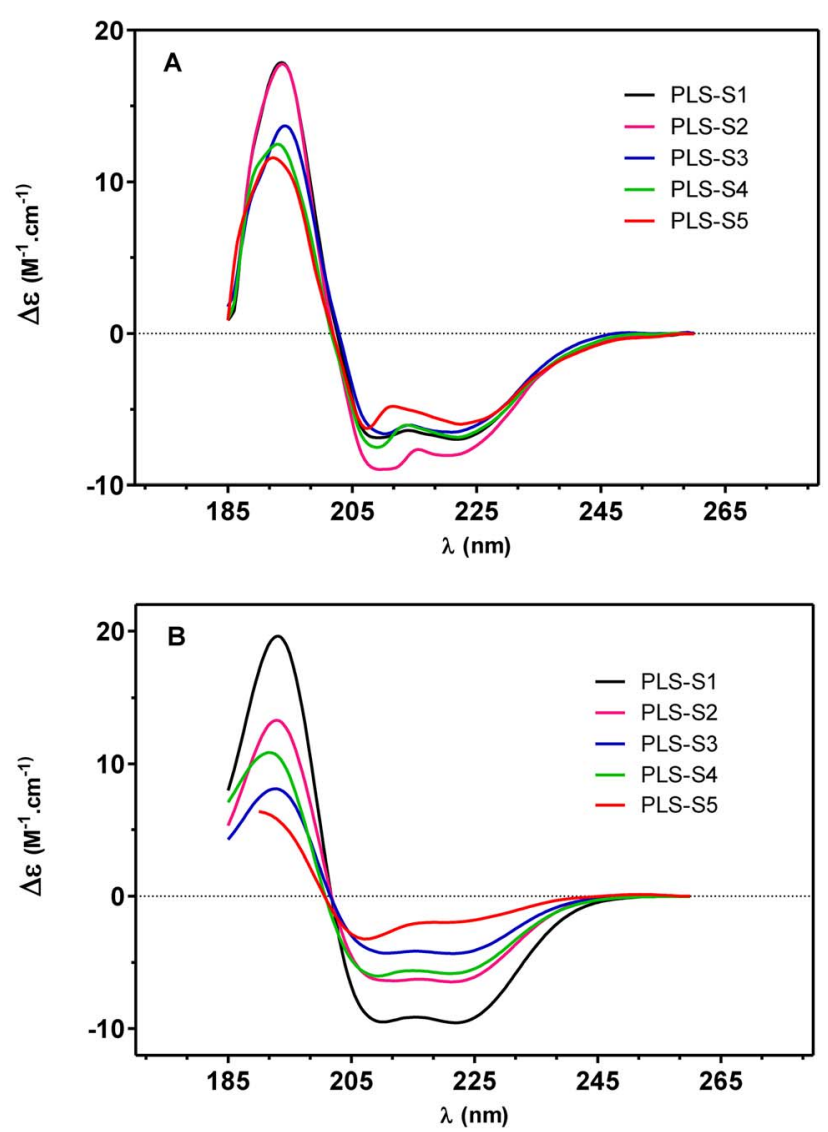

Figure 6. Circular dichroism spectra of synthetic phylloseptins$\mathbf{S}(\mathbf{3 0} \mu \mathbf{M})$. (A) DMPC/DMPG (3:1) large unilamellar vesicles in PBS (1 $\mathrm{mg} / \mathrm{mL}$ ). (B) $80 \mathrm{mM}$ SDS. CD measurements are reported as the dichroic increment $(\Delta \varepsilon)$ per residue.

doi:10.1371/journal.pone.0070782.g006

25922 (>200 $\mu \mathrm{M}$ at pH 7). Moreover, PLS-S1 another peptide containing His residues that is virtually inactive $(\mathrm{MIC}=70 \mu \mathrm{M})$ against E. coli ATCC 25922 was shown to be potent (MIC $=12.5 \mu \mathrm{M})$ at acidic $\mathrm{pH}$. These results indicate that $\mathrm{pH}$ influences the positive net charge of histidines with an impact on the antimicrobial activity.

\section{Killing kinetics of E. coli ML-35p and S. aureus ST1065}

The killing effect of PLSs toward S. aureus ST1065 (PLS-S1, -S2 and -S4) and E. coli ML-35p (PLS-S2 and -S4) was investigated at concentrations corresponding to the MIC $(6.25 \mu \mathrm{M}$ and $25 \mu \mathrm{M}$, respectively) and approximately two-fold above the MIC. The time-kill curves revealed that PLS-S1 and -S2 at concentration two-fold above the MIC caused complete killing of the Grampositive strain S. aureus ST1065 within the first 5 min (Fig. 4). By contrast the killing of $S$. aureus ST1065 by PLS-S4 was slower. Almost similar rapid killing kinetics were observed with PLS-S2 and -S4 against the Gram-negative strain E. coli ML-35p.

\section{Permeabilization/disruption of the Gram-positive and Gram-negative bacterial cytoplasmic membranes}

PLS-induced permeabilization of the cytoplasmic membranes of $S$. aureus ST1065 and E. coli ML-35p was analyzed by incubating the bacteria, which express $\beta$-galactosidase constitutively, with different concentrations of the peptides ( $S$. aureus ST1065: PLS-S1, -S2, and -S4; E. coli ML-35p: PLS-S2 and -S4) and measuring the time-dependent hydrolysis of the small chromogenic substrate 0 nitrophenyl- $\beta$-D-galactopyranoside (ONPG) into o-nitrophenol (ONP) by cytoplasmic $\beta$-galactosidase (Fig. 5). The three peptides permeabilized the bacterial cytoplasmic membrane with increasing severity according to the time and the peptide concentration. The permeabilization was fast and as efficient as with dermaseptin-B2 $(10 \mu \mathrm{M})$, a 34-residue antimicrobial peptide used as positive control, except for PLS-S2 displaying a lower efficiency against $E$. coli ML-35p. It is notable that the membrane permeabilization occurred even at sublethal peptide concentrations and without any discernible lag, indicating that the peptides can directly permeabilize the cytoplasmic membranes. To investigate the mechanism of permeabilization, E. coli ML-35p were incubated with PLS-S2 (30 and $100 \mu \mathrm{M})$ and PLS-S4 (25 and $100 \mu \mathrm{M})$ for $60 \mathrm{~min}$ and $\beta$-galactosidase activity was measured after removing bacteria by centrifugation and adding ONPG to the supernatant. As shown in Fig. 5, a dose-dependent release of $\beta$-galactosidase was detected, indicating that the membrane became leaky to large cytoplasmic components such as $\beta$-galactosidase $(\sim 540 \mathrm{kDa}$, Stokes radius $(\mathrm{Rs})=70 \AA)$. A similar behavior was observed for dermaseptin $\mathrm{B} 2(10 \mu \mathrm{M})$ known to act via a carpet-like mechanism [6]. This is in line with the killing kinetics, suggesting that membrane disruption of bacteria by PLS-S1, -S2 and -S4 induces the leakage of the intracellular content and is concomitant with cell death.

Secondary structure of membrane-bound phylloseptins$S$ inferred from CD spectroscopy and molecular dynamics

The CD spectra of synthetic PLSs $(30 \mu \mathrm{M})$ in aqueous solution or in PBS have a single negative band at $198 \mathrm{~nm}$, typical of peptides in random coil conformation (not shown). When mixed with micellar SDS, a membrane-mimetic environment, the spectra are characteristic of an $\alpha$-helix with a distinct minimum at $222 \mathrm{~nm}$ ( $\mathrm{n}-\pi^{*}$ transition), a second minimum close to $208 \mathrm{~nm}$ (superposition of the random coil $\pi-\pi^{*}$ transition at $200 \mathrm{~nm}$ and the $\alpha$ helix $\pi-\pi^{*}$ transition at $208 \mathrm{~nm}$ ), and the $\alpha$-helix maximum at $193 \mathrm{~nm}$ (Fig. 6). The rank order of peptide helix contents was: PLS-S5 (20\% helix) < PLS-S3 $(44 \%)<$ PLS-S4 (59\%) < PLS-S2 $(65 \%)<$ PLS-S1 $(96 \%)$. Helix formation in the presence of DMPC/DMPG (3:1) large unilamellar vesicles, a bacterial membrane-mimic, follows almost the same trend, i.e. PLS-S5 $(60 \%$ helix $)<$ PLS-S3 $(65 \%$ helix $)<$ PLS-S4 $(68 \%$ helix $)<$ PLSS1 $(70 \%$ helix $)<$ PLS-S2 (80\% helix). Placing the amino acid sequence of PLSs on a Schiffer-Edmundson wheel projection reveals that the peptides can adopt an amphipathic structure with two separated clusters of hydrophobic and hydrophilic/basic residues located on opposing sides of the helical wheel (Fig. 7). One face of the helix subtending a radial angle of $220-270^{\circ}$ perpendicular to the long axis demonstrates a marked hydrophobic character with strongly and bulky apolar residues (Leu, Ile, and Phe) forming a broad and highly prominent hydrophobic patch all along the helix length. The opposite face of the helix containing one to three basic residues (Lys, His) is composed of neutral glycine and small polar residues (Ser). Accordingly, the helical hydrophobic moment of the peptides $\langle\mu \mathrm{H}\rangle$, a measure of the amphiphilicity of the helix, was $0.35-0.55$, whereas the peptide hydrophobicity $\langle\mathrm{H}\rangle=0.79-0.95$ (Table 1) [29]. We have performed in silico studies to visualize the interaction of the potent PLS-S2 with an E. coli membrane model. Docking using Hex 6.3 software showed that non-structured PLS-S2 does not interact with the membrane surface whereas $\alpha$-helical PLS-S2 binds and inserts into the hydrophobic core of the bilayer (Fig. 8). 

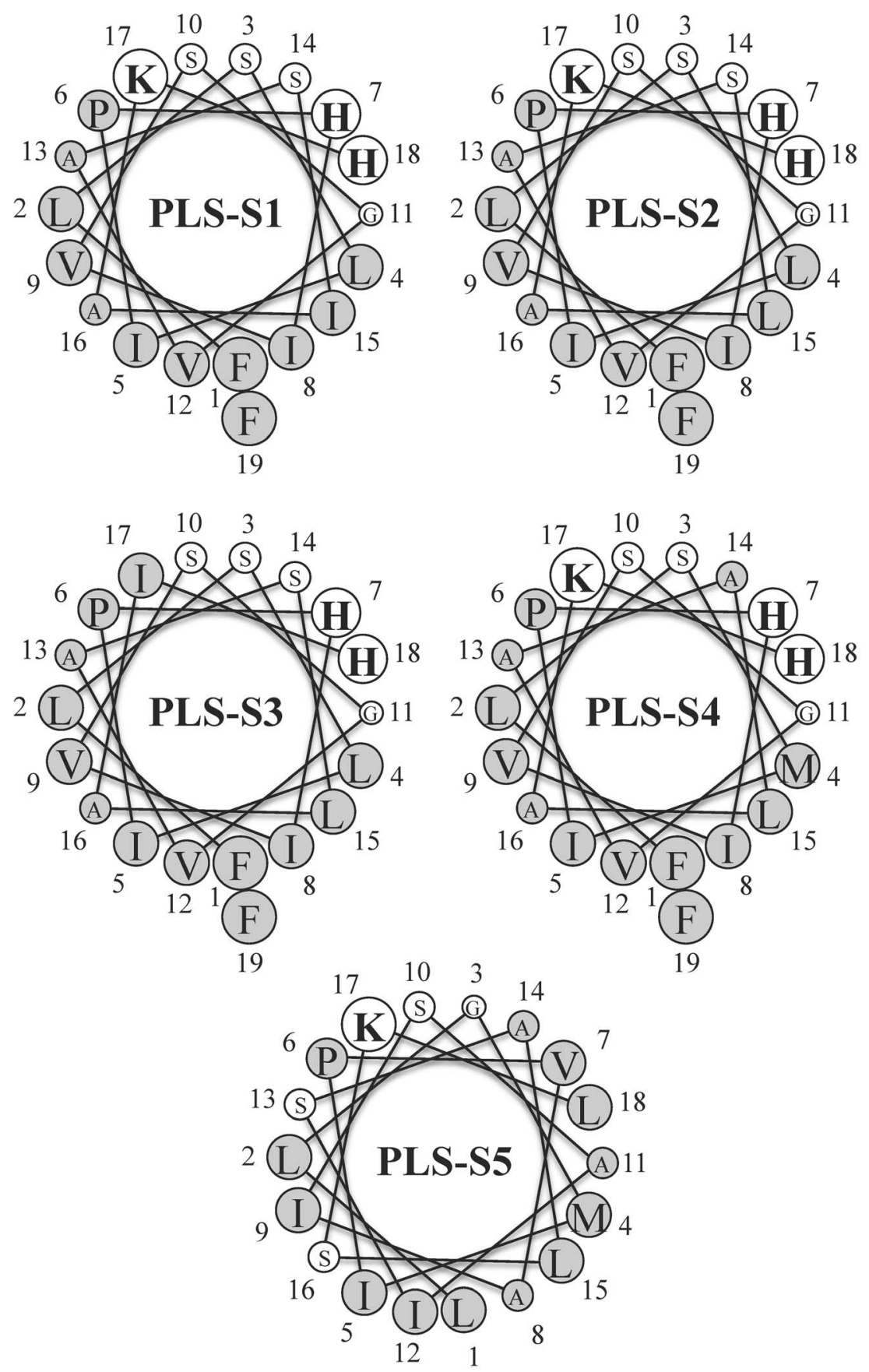

Figure 7. Helical wheel diagram of the different phylloseptins-S. Residues are circled proportionally to amino acid volume. Apolar residues are colored in grey and polar residues are in white. Basic residues are indicated in bold.

doi:10.1371/journal.pone.0070782.g007

Comparing the interactions of phylloseptins-S with zwitterionic and anionic model membranes by differential scanning calorimetry

Differential scanning calorimetry was used to study the thermotropic behavior of DMPG and DMPG multilamellar vesicles $(\mathrm{MLVs})$ upon addition of PLSs. The peptides were added at different concentrations after liposomes were formed to ensure that they could only interact with the external surface of the MLVs. DMPG was chosen as a model system for bacterial membranes because they contain substantial (up to 30\%) amounts of negatively charged lipids such as phosphatidylglycerol and cardiolipin. DMPC, a zwitterionic phospholipid, was used as a model for mammalian cell membranes. In the absence of peptide, DMPG and DMPG MLVs exhibit a strongly endothermic and highly cooperative main transition on heating near $23^{\circ} \mathrm{C}$ (DMPG) or $24^{\circ} \mathrm{C}$ (DMPG) (conversion of the rippled gel phase to the fluid lamellar liquid-crystalline phase L $\alpha$ ) [30] (Fig. 9). The main phase transition (chain melting) is mainly due to trans-gauche isomerization of the acyl chains, which decreases the acyl chain packing of the lipid molecules, increasing fluidity of the membrane. Therefore, the effect of added peptides on the temperature (Tm), enthalpy 

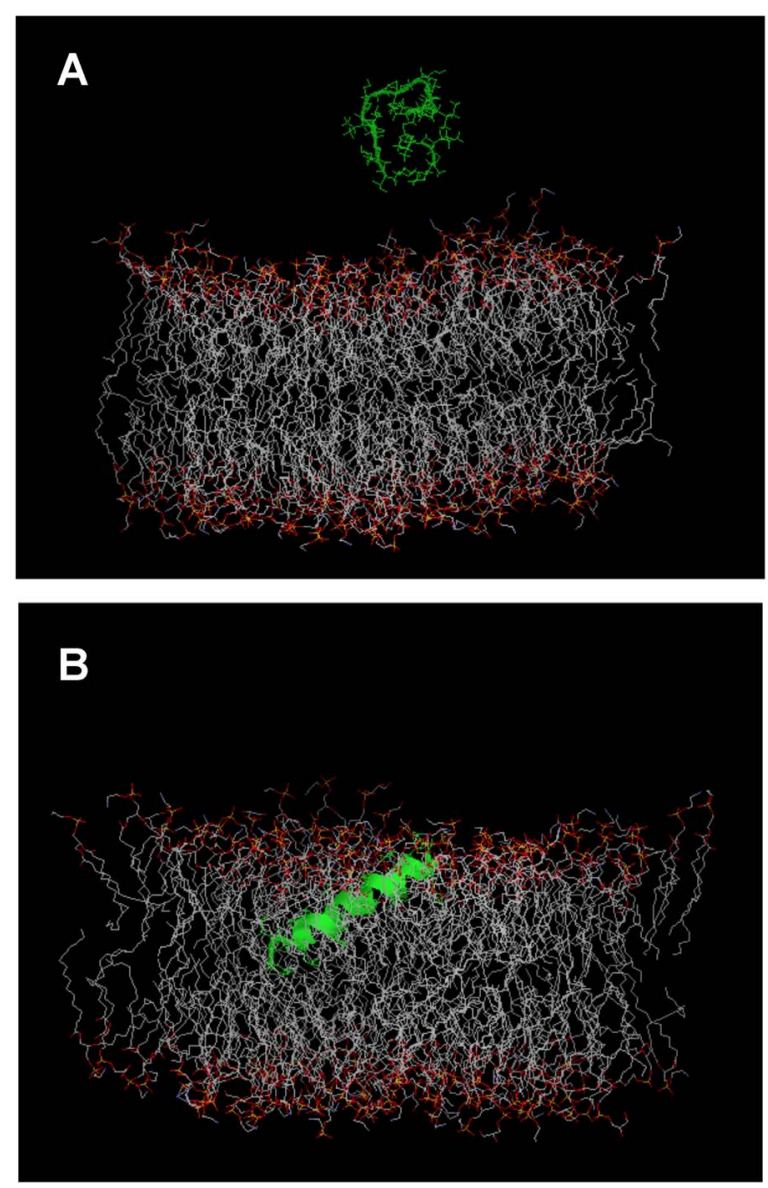

Figure 8. PLS interactions with bacterial membrane studied by molecular dynamic simulations. PLS-S2 was simulated with an $E$. coli membrane bilayer model [26] using the software Hex 6.3. PDB files generated were visualized using Rasmol 2.7.5.2. No docking is observed for the non-structured PLS-S2 $\left(\mathrm{H}_{2} \mathrm{O}\right)(\mathrm{A})$ whereas an insertion into the lipid bilayer is predicted for the peptide in $\alpha$-helical structure (B). doi:10.1371/journal.pone.0070782.g008

$(\Delta \mathrm{H})$, and cooperativity $\left(\Delta \mathrm{T}_{1 / 2}\right)$ of the main transition serves as an indicator of the ability of the peptide to interact with lipid head groups and to perturb the packing of the lipid acyl chains [31-33]. Binding of PLS-S1, -S2 and -S4 (peptide/lipid ratio 1:100) to negatively charged MLVs strongly reduces the enthalpy of the main phase transition, together with an enhanced broadening of the peak, indicating fluidification of the membrane and lower packing, and van der Waals attraction between lipid molecules as a result of penetration of the peptide into the hydrophobic domain of the bilayer (Fig. 9, Table 4). Increasing quantities of the peptides (peptide/lipid ratio 1:50) induced a two-component main phase transition, consisting of a broad higher-temperature and less cooperative component superimposed over a sharper lowertemperature component, and a marked decrease $(\sim 50-80 \%)$ in the total enthalpy of the main phase transition (the sum of all the components observed). Using the rationale provided by previous studies [34], the sharp low-temperature and broad high-temperature components of the DSC thermograms were assigned to the chain melting phase transition of peptide-poor and peptide-rich phospholipid domains, respectively. The decrease in the temperature and cooperativity of the sharp component may be attributable to domain boundary effects arising from the decreasing size of the peptide-poor lipid domain. These results indicate that PLSs strongly and selectively perturbs anionic bilayer membranes by interacting with the polar head groups and acyl region of the phospholipids, hence disrupting the acyl chain packing of the bilayer. In accordance with their significant hemolytic and cytotoxic activities, binding of PLS-S1, -S2 and S4 (peptide/lipid ratio 1:50) to zwitterionic DMPC vesicles also lead to a significant decrease $(\sim 40-70 \%)$ in the enthalpy of the main transition (Fig. 9, Table 4). However, no significant effect on the temperature and cooperativity of the main phase transition was observed, indicating that the peptides interacted with the polar head groups and glycerol backbone region of the phospholipids only $[6,25]$.

\section{Discussion}

Phylloseptins-S produced by the skin of $P$. sauvagii are paralogs of similar length (18-19 amino acid residues) but differ markedly in net charge, degree of structure formation, and amphipathicity. They are thus good models for structure-function relationship studies to shed light on the role these parameters play on the ability of these peptides to bind to and disrupt microbial membranes. PLS-S1, -S2 and -S4 have identical net charges $(+2)$, mean hydrophobicities $(<\mathrm{H}>\sim 0.80)$, and helix-forming propensities $(68-80 \%$ helix). They adopt an $\alpha$-helical amphipathic structure in membrane environments $(\langle\mu \mathrm{H}\rangle \sim 0.55)$, with two well-separated clusters of hydrophobic and hydrophilic/basic residues located on opposing sides of the helix. PLS-S1, -S2 and -S4 induced strong perturbations in the chain packing of anionic lipid bilayers that are consistent with deep penetration of the hydrophobic sector of the peptide helix into the fatty acyl chains of the bilayer, with formation of regions of two coexisting phases, one phase rich in peptide and the other lipid-rich. This gradual phase segregation between peptide-poor and peptide-rich domains leads to membrane permeation/disruption. Accordingly, the three peptides show potent bactericidal activities by compromising the structural and functional integrity of the plasma bilayer of the target cells.

Cationic antimicrobial peptides of the $\alpha$-helical class have a net positive charge of at least +2 [35], which is essential for their mechanism of action because the positively charged polar face of the peptide helix will drive the initial attraction to the negatively charged components of the microbial membrane through long range electrostatic interactions. PLS-S2 and PLS-S3 only differ by one amino acid. Whereas PLS-2 carries a lysine in position 17, an isoleucine is located at the same position of PLS-3. Although the two peptides have similar overall helix-forming propensities (65$80 \%$ helix) and amphipathicities $(<\mu \mathrm{H}\rangle=0.43-0.55)$, the most pronounced difference is the variation of their net charge at physiological $\mathrm{pH}$. Whereas PLS-S2 (net charge $=+2$ ) was active against most of the tested microorganisms at $\mu \mathrm{M}$ concentrations, PLS-S3 (net charge $=+1$ ) was virtually inactive. This adds further support to the view that a positive net charge of at least +2 is a key factor for potent antimicrobial activity in $\alpha$-helical amphipathic peptides. Although histidine side chain has a $\mathrm{pKa}$ value close to 6.5 when in an unstructured polypeptide chain, thus being only weakly charged at $\mathrm{pH} \geq 7$, note, however, that the ionization state of the His residue can be modulated by hydrophobic, electrostatic and polar interactions with anionic surfaces. For instance, a large shift of $\mathrm{pKa}$ of the His residue to a much higher value is expected if $\mathrm{His}$ acts as a hydrogen bond donor to form a $\mathrm{H}$-bond with the anionic head groups of negatively charged bilayers via its $\mathrm{N} \delta 1 \mathrm{H}^{+}$ or $\mathrm{N} \varepsilon 2 \mathrm{H}^{+}$groups [36].

A fine balance of electrostatic and hydrophobic interactions is needed to assure for membrane association and formation of an 
PLS-S/DMPG

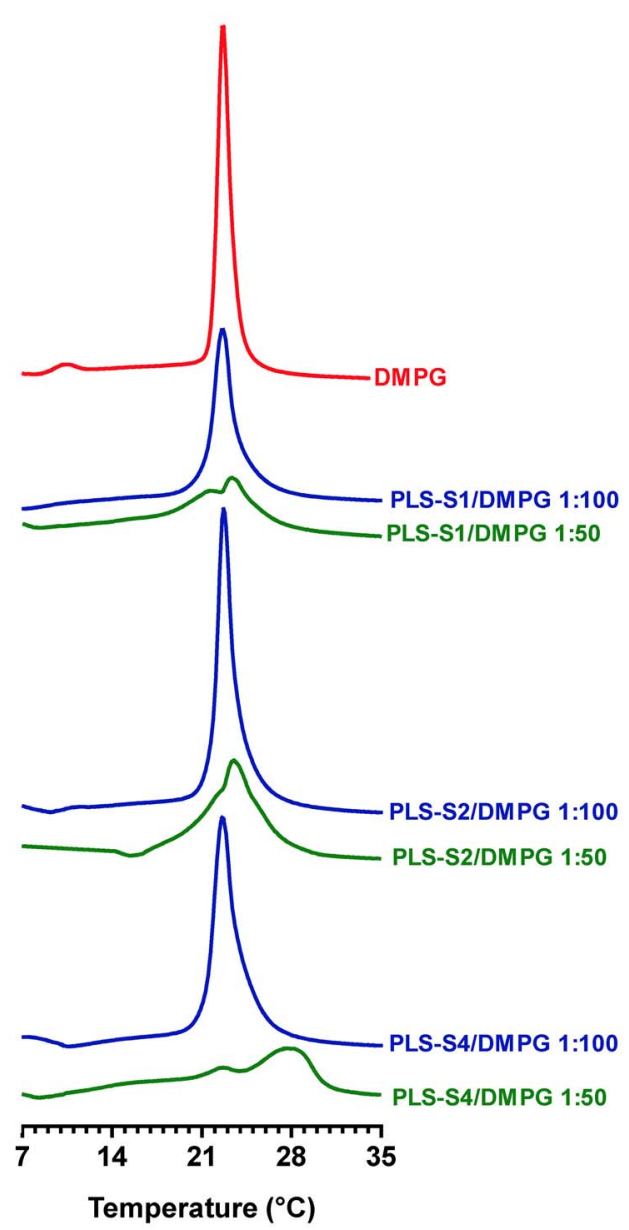

PLS-S/DMPC

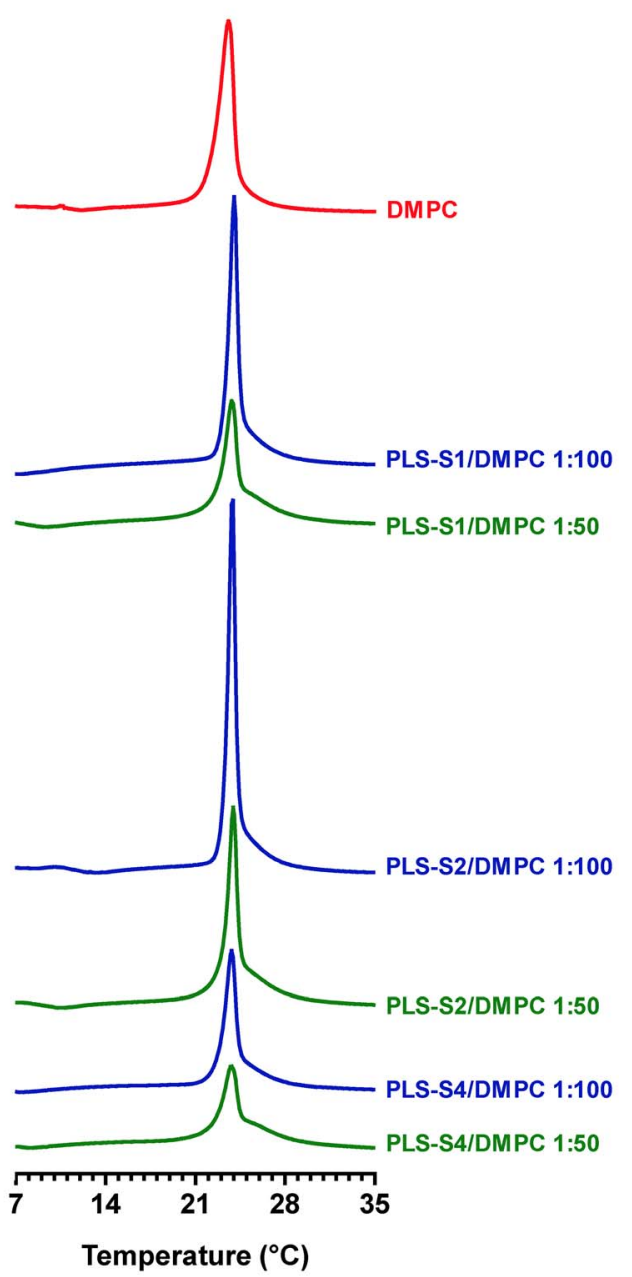

Figure 9. DSC heating thermograms for DMPG and DMPC multilamellar vesicles with or without PLS-S1, -S2 and -S4. Scans were acquired at different peptide/lipid molar ratios (red, lipid control w/o peptide; blue, 1:100; green, 1:50;). doi:10.1371/journal.pone.0070782.g009

amphipathic helical structure with a high hydrophobic moment, thereby promoting membrane insertion and disruption. There is good agreement that cationic $\alpha$-helical AMPs are attracted by the bacterial membranes by electrostatic interactions and then undergo conformational changes during membrane interactions. The coil-helix transition contributes about $0.5 \mathrm{kcal} / \mathrm{mol}$ per residue to the membrane binding energy of amphipathic peptides [37], which should promote the membrane association. Once bound, with its helix axis parallel to the bilayer surface, the peptide would insert the hydrophobic face of the helix within the membrane interior through hydrophobic and van der Waals interactions, causing local fusion of the membrane leaflets, pore formation, cracks and membrane disruption.

PLS-S5 has a net charge of +2 but is virtually inactive against microorganisms. Among the phylloseptins-S, PLS-S5 has the lowest helix-forming propensity and amphipathicity. It is thus likely that the differences in antimicrobial efficacies of PLS-S5 and PLS-S1, S2 and -S4 may reflect differences between the degree of helix formation and/or amphipathicity of these peptides. First, two basic residues $\left(\mathrm{Lys}^{17}\right.$ and His ${ }^{18}$ ) are found for PLS-S1, -S2 and -S4 at the C-terminus of the helix. As shown by Resende et al. [17] and previous investigations [38], the interactions of the helix dipole with a positively charged side chain, histidine in particular, positioned at the C-terminus of the helix have strong helix stabilizing properties. This effect is less pronounced for PLS-S5 that carries only one lysine residue in this region. An additional energy contribution to helix stabilization of PLS-S1, -S2 and -S4 versus PLS-S5 invokes cation- $\pi$ interactions between $\mathrm{His}^{18}$ and $\mathrm{Phe}^{19}$ that could promote helical conformations at the C-terminus $[17,39]$.

Second, PLS-S1, -S2 and -S4 form well-behaved amphipathic $\alpha$-helices once bound to anionic membrane-mimetics. One face of the helix demonstrates a marked hydrophobic character with strongly and bulky apolar residues (Leu, Ile, and Phe) forming a highly prominent and uninterrupted hydrophobic patch all along the helix length. Phe residues are known to act as amphipathic inplane membrane anchors [40]. The opposite face of the helix is composed by an alternation of basic residues, neutral glycine and polar residues (Ser). Accordingly, the helical hydrophobic moment of the peptide $\langle\mu \mathrm{H}\rangle$, a measure of the amphiphilicity of the helix, is $0.52-0.55$. In contrast, the polar helical surface of PLS-S5 is rather small, being constituted of only a lysine, a glycine and a serine. In addition, two polar residues (Ser) interrupt the continuity of the opposite shallow apolar face of the helix cylinder. Accordingly, the helix formed by PLS-S5 has very low amphipathicity $(<\mu \mathrm{H}>=0.35)$. 
Table 4. PLS-S effect on the thermotropic behavior of DMPG and DMPC MLVs.

\begin{tabular}{lll}
\hline & \multicolumn{1}{c}{$\Delta \mathbf{T}_{\mathbf{m}}, \mathbf{C}$} & $\boldsymbol{\Delta}(\boldsymbol{\Delta} \mathbf{H}), \%$ \\
\hline DPMG & & \\
PLS-S1/DMPG 1:100 & 0 & -53.4 \\
PLS-S1/DMPG 1:50 & $-1 / 0.6^{*}$ & -75.9 \\
PLS-S2/DMPG 1:100 & 0 & -30.2 \\
PLS-S2/DMPG 1:50 & $-1.1 / 0.8^{*}$ & -50.0 \\
PLS-S4/DMPG 1:100 & 1.1 & -25.9 \\
PLS-S4/DMPG 1:50 & $-0.1 / 5.1^{*}$ & -80.2 \\
DPMC & & \\
PLS-S1/DMPC 1:100 & 0.3 & -53.3 \\
PLS-S1/DMPC 1:50 & 0.1 & -70.1 \\
PLS-S2/DMPC 1:100 & 0.2 & -19.6 \\
PLS-S2/DMPC 1:50 & 0.2 & -40.8 \\
PLS-S4/DMPC 1:100 & 0.1 & -60.9 \\
PLS-S4/DMPC 1:50 & 0 & -66.9 \\
\hline DMPG:12- & & \\
\hline
\end{tabular}

DMPG: 1,2-dimyristoyl-sn-glycero-3-phosphoglycerol; DMPC: 1,2-dimyristoyl-snglycero-3-phosphocholine; MLVs: multilamellar vesicles. Variations of the temperature and total enthalpy values of the main transition phase are indicated as $\Delta \mathrm{T}_{\mathrm{m}}\left(\mathrm{T}_{\mathrm{m}}-\mathrm{T}_{\mathrm{m}}\right.$ w/o peptide $)$ and $\% \Delta(\Delta \mathrm{H})[(\Delta \mathrm{H}-\Delta \mathrm{H}$ w/o peptide $) \times 100 /$ $\Delta \mathrm{H}_{\text {w/o peptide }] . ~}{ }^{*} \Delta \mathrm{T}_{\mathrm{m}}$ of the two observed components. $\mathrm{T}_{\mathrm{m}}$ and $\Delta \mathrm{H}$ values were estimated by a peak-fitting procedure using $\mathrm{CpCalc}$ software and correspond to the mean obtained from six scans.

doi:10.1371/journal.pone.0070782.t004

Phylloseptins-S displayed antibacterial activities against Gramnegative and Gram-positive bacteria, as well as antiparasitic activity against promastigote of Leishmania sp. They however exhibit also a significant toxicity against mammalian cells. Hydrophobicity of cationic $\alpha$-helical amphipathic peptides appears to have a higher impact on mammalian cell toxicity than on antibacterial action. Highly hydrophobic peptides are related to higher hemolysis and a decrease in discrimination between host cytotoxicity and antimicrobial activity. Phylloseptins-S are highly hydrophobic and only mildly cationic. Although basic peptides

\section{References}

1. Nicolas P, El Amri C (2009) The dermaseptin superfamily: a gene-based combinatorial library of antimicrobial peptides. Biochim Biophys Acta 1788: 1537-1550.

2. Nicolas P, Ladram A (2013) Dermaseptins. In: Kastin AJ, editor, Handbook of Biologically Active Peptides, Second edition. Elsevier. 350-363.

3. Vanhoye D, Bruston F, Nicolas P, Amiche M (2003) Antimicrobial peptides from hylid and ranin frogs originated from a 150-million-year-old ancestral precursor with a conserved signal peptide but a hypermutable antimicrobial domain. Eur J Biochem 270: 2068-2081.

4. Shai Y (1999) Mechanism of the binding, insertion and destabilization of phospholipid bilayer membranes by $\alpha$-helical antimicrobial and cell nonselective membrane-lytic peptides. Biochim Biophys Acta 1462: 55-70.

5. Lequin O, Bruston F, Convert O, Chassaing G, Nicolas P (2003) Helical structure of dermaseptin $\mathrm{B} 2$ in a membrane-mimetic environment. Biochemistry 42: 10311-10323.

6. Galanth C, Abbassi F, Lequin O, Ayala-Sanmartin J, Ladram A, et al. (2009) Mechanism of antibacterial action of dermaseptin B2: interplay between helixhinge-helix structure and membrane curvature strain. Biochemistry 48: 313327.

7. Nicolas P (2009) Multifunctional host defense peptides: intracellular-targeting antimicrobial peptides. FEBS J 276: 6483-96.

8. Duda TF Jr, Vanhoye D, Nicolas P (2002) Roles of diversifying selection and coordinated evolution in the evolution of amphibian antimicrobial peptides. Mol Biol Evol 19: 858-864.

9. Nicolas P, Vanhoye D, Amiche M (2003) Molecular strategies in biological evolution of antimicrobial peptides. Peptides 24: 1669-1680. interact much better with anionic membranes, and to a lesser degree with zwitterionic membranes, it has been shown that hydrophobic effects should account for the binding capacity of neutral peptides to anionic lipids [36]. This stresses the importance of hydrophobic interactions between the peptides and the lipid bilayer for helix formation and stabilization.

\section{Supporting Information}

Figure S1 MALDI-TOF MS spectrum of the HPLC fractions containing (A) PLS-S4 (fraction $53 \mathrm{~min}$ ), (B) PLS-S1/S2 (fraction $54 \mathrm{~min}$ ), and (C) PLS-S5 (fraction $62 \mathrm{~min})$. The $[\mathrm{M}+\mathrm{H}]^{+}$ion of the corresponding mature peptides is indicated with a circle. Lower panel, zoom of the MS spectrum showing sodium and potassium adducts (PLS-S1/S2 and PLS-S5) and also the oxidation of the methionine (PLS-S5, Ox Met: methionine sulfoxide).

(TIFF)

Figure S2 MALDI-TOF-TOF MS/MS spectra obtained from collision-induced dissociation of the phylloseptinsS parent ions. (A) PLS-S4, $[\mathrm{M}+\mathrm{H}]^{+}=2003$; (B) PLS-S1/S2, $[\mathrm{M}+\mathrm{H}]^{+}=2035$; (C) PLS-S5: $[\mathrm{M}+\mathrm{H}]^{+}=1796$. Lower panel, band y-ion series. For each PLS-S, the sequence was obtained with remaining leucine/isoleucine indeterminations.

(TIFF)

\section{Acknowledgments}

E. coli ML-35p and S. aureus ST1065 bacterial strains were kindly supplied by Prof. S. Rebuffat (UMR 7245 GNRS/Muséum National d'Histoire Naturelle, Paris, France) and Dr. T. Msadek (Biology of Gram-Positive Pathogens, Institut Pasteur, Paris, France), respectively. We thank Dr. G. Bolbach and G. Clodic (Plate-forme de Spectrométrie de Masse et Protéomique, IFR83, UPMC Univ Paris 06, France) for mass spectrometry analysis.

\section{Author Contributions}

Conceived and designed the experiments: ZR SA DS PN TF BO AL. Performed the experiments: ZR SA CP BO AL. Analyzed the data: ZR SA DS PN TF BO AL. Contributed reagents/materials/analysis tools: DS TF BO AL. Wrote the paper: ZR PN AL.

10. Leite R, Silva LP, Rodrigues MI, Prates MV, Brand GD, et al. (2005) Phylloseptins: a novel class of anti-bacterial and anti-protozoan peptides from the Phyllomedusa genus. Peptides 26: 565-573.

11. Chen T, Zhou M, Gagliardo R, Walker B, Shaw C (2006) Elements of the granular gland peptidome and transcriptome persist in air-dried skin of the South American orange - legged leaf frog, Phyllomedusa hypocondrialis. Peptides 27: 2129-2136.

12. Conceição K, Konno K, Richardson M, Antoniazzi LM, Jared C, et al. (2006) Isolation and biochemical characterization of peptides presenting antimicrobial activity from the skin of Phyllomedusa hypochondrialis. Peptides 27: 3092-3099.

13. Conlon JM, Woodhams DC, Raza H, Coquet L, Leprince J, et al. (2007) Peptides with differential cytolytic activity from skin secretions of the lemur leaf frog Hylomantis lemur (Hylidae: Phyllomedusinae). Toxicon 50: 498-506.

14. Abdel-Wahab YH, Power GJ, Flatt PR, Woodhams DC, Rollins-Smith LA, et al. (2008) A peptide of the phylloseptin family from the skin of the frog Hylomantis lemur (Phyllomedusinae) with potent in vitro and in vivo insulin-releasing activity. Peptides 29: 2136-2143.

15. Zhang R, Zhou M, Wang L, McGrath S, Chen T, et al. (2010) Phylloseptin-1 (PSN-1) from Phyllomedusa sauvagei skin secretion: a novel broad-spectrum antimicrobial peptide with antibiofilm activity. Mol Immunol 47: 2030-2037.

16. König E, Clark VC, Shaw C, Bininda-Emonds OR (2012) Molecular cloning of skin peptide precursor-encoding cDNAs from tibial gland secretion of the Giant Monkey Frog, Phyllomedusa bicolor (Hylidae, Anura). Peptides 38: 371-376.

17. Resende JM, Moraes CM, Prates MV, Cesar A, Almeida FG, et al. (2008) Solution NMR structures of the antimicrobial peptides phylloseptin-1, -2, and -3 and biological activity: the role of charges and hydrogen bonding interactions in stabilizing helix conformations. Peptides 29: 1633-1644. 
18. Kückelhaus SA, Leite JR, Muniz-Junqueira MI, Sampaio RN, Bloch Jr C, et al. (2009) Antiplasmodial and antileishmanial activities of phylloseptin-1, an antimicrobial peptide from the skin secretion of Phyllomedusa azurea (Amphibia). Exp Parasitol 123: 11-16

19. Lequin O, Ladram A, Chabbert L, Bruston F, Convert O, et al. (2006) Dermaseptin S9, an alpha-helical antimicrobial peptide with a hydrophobic core and cationic termini. Biochemistry 45: 468-480.

20. Abbassi F, Raja Z, Oury B, Gazanion E, Piesse C, et al. (2013) Antibacterial and leishmanicidal activities of temporin-SHd, a 17-residue long membranedamaging peptide. Biochimie 95: 388-399.

21. Abbassi F, Oury B, Blasco T, Sereno D, Bolbach G, et al. (2008) Isolation, characterization and molecular cloning of new temporins from the skin of the North African ranid Pelophylax saharica. Peptides 29: 1526-1533.

22. Luplertlop N, Surasombatpattana P, Patramool S, Dumas E, Wasinpiyamongkol L, et al. (2011) Induction of a peptide with activity against a broad spectrum of pathogens in the Aedes aegypti salivary gland, following Infection with Dengue Virus. PLoS Pathog 7: e1001252.

23. Roy G, Dumas C, Sereno D, Wu Y, Singh AK, et al. (2000) Episomal and stable expression of the luciferase reporter gene for quantifying Leishmania spp. infections in macrophages and in animal models. Mol Biochem Parasitol 110: 195-206.

24. Abbassi F, Lequin O, Piesse C, Goasdoué N, Nicolas P, et al. (2010) Temporin$\mathrm{SHf}$, a new type of phe-rich and hydrophobic ultrashort antimicrobial peptide. J Biol Chem 285: 16880-16892.

25. Abbassi F, Galanth G, Amiche M, Saito K, Piesse C, et al. (2008) Solution structure and model membrane interactions of temporins-SH, antimicrobial peptides from amphibian skin. A NMR spectroscopy and differential scanning calorimetry study. Biochemistry 47: 10513-11525.

26. Pandit KR, Klauda JB (2012) Membrane models of $E$. coli containing cyclic moieties in the aliphatic lipid chain. Biochim Biophys Acta 1818: 1205-1210.

27. Toukan K, Rahman A (1985) Molecular-dynamics study of atomic motions in water. Phys Rev B 31: 2643-2648.

28. Amiche M, Ladram L, Nicolas P (2008) A consistent nomenclature of antimicrobial peptides isolated from frogs of the subfamily Phyllomedusinae. Peptides 29: 2074-2082.

29. Gautier R, Douguet D, Antonny B, Drin G (2008) HELIQUEST: a web server to screen sequences with specific $\alpha$-helical properties. Bioinformatics 24: 21012102
30. Zhang YP, Lewis RNHA, McElhaney RN (1997) Calorimetric and spectroscopic studies of the thermotropic phase behavior of the n-saturated 1,2diacylphosphatidylglycerols. Biophys J 72: 779-793.

31. Henzler-Wildman KA, Martinez GV, Brown MF, Ramamoorthy A (2004) Perturbation of the hydrophobic core of lipid bilayers by the human antimicrobial peptide LL-37. Biochemistry 43: 8459-8469.

32. Lohner K, Prenner EJ (1999) Differential scanning calorimetry and X-ray diffraction studies of the specificity of the interaction of antimicrobial peptides with membrane-mimetic systems. Biochim Biophys Acta 1462: 141-156.

33. McElhaney RN (1986) Differential scanning calorimetric studies of lipid-protein interactions in model membrane systems. Biochim Biophys Acta 864: 361-421.

34. Seto GWJ, Marwaha S, Kobewka DM, Lewis RN, Separovic F, et al. (2007) Interactions of the Australian tree frog antimicrobial peptides aurein 1.2, citropin 1.1 and maculatin 1.1 with lipid model membranes: differential scanning calorimetric and Fourier transform infrared spectroscopic studies. Biochim Biophys Acta 1768: 2787-2800.

35. Jiang Z, Vasil AI, Hale JD, Hancock RE, Vasil ML, et al. (2008) Effects of net charge and the number of positively charged residues on the biological activity of amphipathic alpha-helical cationic antimicrobial peptides. Biopolymers 90: 369383.

36. Vanhoye D, Bruston F, El Amri S, Ladram A, Amiche M, et al. (2004) Membrane association, electrostatic sequestration, and cytotoxicity of Gly-Leurich peptide orthologs with differing functions. Biochemistry 43: 8391-409.

37. Wieprecht T, Apostolov O, Beyermann M, Seelig J (1999) Thermodynamics of the alpha-helix-coil transition of amphipathic peptides in a membrane environment: implications for the peptide-membrane binding equilibrium. J Mol Biol 294: 785-794.

38. Armstrong KM, Baldwin RL (1993) Charged histidine affects alpha-helix stability at all positions in the helix by interacting with the backbone charges. Proc Natl Acad Sci USA 90: 11337-1140.

39. Shi Z, Olson CA, Bell AJ Jr, Kallenbach NR (2001) Stabilization of alpha-helix structure by polar side-chain interactions: complex salt bridges, cation-pi interactions, and C-H leader O H-bonds. Biopolymers 60: 366-380.

40. Sapay N, Dermeneur Y, Deléage G (2006) Prediction of amphipathic in-plane membrane anchors in monotopic proteins using a SVM classifier. Bioinformatics 7: 255 . 